\title{
Novel Ceramic Membrane for High Temperature Carbon Dioxide Separation
}

Technical Progress Report (Semi-Annual)

$09 / 01 / 01$

$02 / 28 / 02$

\author{
Jun-ichi Ida \\ Zhaohui Yang \\ Jerry Y. S. Lin
}

March 2002

DE-FG26-00NT40824

\author{
University of Cincinnati \\ Department of Chemical Engineering \\ Mail Location 171 \\ Cincinnati, OH 45221-0171
}




\section{DISCLAIMER}

"This report was prepared as an account of work sponsored by an agency of the United States Goverment. Neither the United State Government nor any agency thereof, nor any of their employees, makes any warranty, express or implied, or assumes any legal libability or responsibility for the accuracy, completeness, or usefulness of any information, apparatus, product, or process disclosured, or represents that its use would not infringe privately owed rights. Reference herein to any specific commercial product, process, or service by trade name, trademark, manufacturer, or otherwise does not necessarily constitute or imply its endorsement, recommendation, or favorig by the United States Government or any agency thereof. The views and opinions of authers expressed herein do not necesssarily state or reflect those of the United State Governmentor any agency thereof". 


\section{ABSTRACT}

A double layer model to describe the mechanism of $\mathrm{CO}_{2}$ sorption/desorption for both pure and modified lithium zirconate was proposed based on the all data obtained so far with the help of TGA, DSC and XRD analysis. The model can elucidate well the $\mathrm{CO}_{2}$ sorption/desorption behavior of lithium zircocnate in both pure and modified cases.

\section{TABLE OF CONTENT}

Disclaimer

Abstract

Lists of Graphical Materials

Exective Summary

Introduction

Experimental

Results and Discussion

Conclusion

\section{LISTS OF GRAPHICAL MATERIALS}

Figure 1 Schematic illustration of carbonation mechanism on pure and modified $\mathrm{Li}_{2} \mathrm{ZrO}_{3}$ 


\section{INTRODUCTION}

Development of carbon dioxide separation technology from various gas streams at high temperatures $\left(400-700{ }^{\circ} \mathrm{C}\right)$ is very important to the reduction of the carbon dioxide emission to the atmosphere. For example, the flue gas from the coal-burner is hot and its temperatures vary from a few hundreds to about a thousand degrees Celsius depending on the specific locations in the flue gas line in the coal-burning power plant. It is highly desirable to separate $\mathrm{CO}_{2}$ from flue gas at a high temperature (for example, around $350^{\circ} \mathrm{C}$ after the economizer) without cooling the flue gas to room or even lower temperature. The high temperature $\mathrm{CO}_{2}$ separation process would produce concentrated, warm $\mathrm{CO}_{2}$ which can be subsequently used directly as feedstock for high temperature chemical synthesis of fuels (e.g., methanol or chemicals).

In the above application, incorporation of a high temperature $\mathrm{CO}_{2}$ separation process would significantly improve the efficiency and economics of overall processes for power generation and carbon dioxide sequestration. Adsorption and membranes are relatively new separation technologies. Membrane process is generally more energy efficient and easier to operate than the adsorption process. But it is more difficult to prepare a good quality $\mathrm{CO}_{2}$ permselective membrane than to prepare a similar sorbent. Various adsorbents for selective sorption of $\mathrm{CO}_{2}$ have been studied for many years. For the past few years development of inorganic membranes for carbon dioxide separation has also received increasing attention. However, few adsorbents or membranes reported so far have desired properties for high temperature $\mathrm{CO}_{2}$ separation.

Phase I research was proposed to develop inorganic membrane for carbon dioxide separation from flue (or coal gasification gas) in the temperature range of $350-550^{\circ} \mathrm{C}$. We conducted many experiments in YEAR I to identify the microstructure and $\mathrm{CO}_{2}$ sorption mechanism for a unique ceramic material (lithium zirconate) with good properties for $\mathrm{CO}_{2}$ separation in this temperature range. Based on the results obtained in YEAR I we developed a double layer model to describe the mechanism of $\mathrm{CO}_{2}$ sorption/desorption for both pure and modified lithium zirconate.

\section{PROPOSED CO $\mathrm{CO}_{2}$ SORPTION MECHANISM}

Based on the all obtained results in Year I research, we proposed a mechanism of $\mathrm{CO}_{2}$ sorption on pure and modified lithium zirconate shown in Fig. 1. When pure lithium zirconate is exposed to $\mathrm{CO}_{2}$ at $500^{\circ} \mathrm{C}$ (Fig.1 (a) to (b)), $\mathrm{CO}_{2}$ molecules move to the surface of the lithium zirconate and react with lithium zirconate to form solid zirconium oxide (monoclinic phase) and lithium carbonate. The initial period of the relative faster increase in the $\mathrm{CO}_{2}$ sorption uptake may correspond to the carbonation process before the formation of a dense lithium carbonate shell on the outer surface and a dense zirconium oxide shell in the middle covering the unreacted lithium zirconate core. Zirconium oxide and lithium carbonate shells are both in solid state because their melting points are higher than the temperature for $\mathrm{CO}_{2}$ sorption. After the formation of the two lithium carbonate 
and zirconium oxide shells, the carbonation reaction can continue, but at a much slower rate. As shown in Fig. 1, $\mathrm{CO}_{2}$ may diffuse through the solid lithium carbonate shell, and react with $\mathrm{Li}^{+}$and $\mathrm{O}^{2-}$ on the outer surface of the zirconium oxide shell. Another reaction occurs on the surface of the unreacted lithium zirconate to generate $\mathrm{Li}^{+}$and $\mathrm{O}^{2-}$. It is well known that zirconium oxide contains a considerable number of defects in its crystals including oxygen vacancy $(1,2)$. Oxygen ions can jump through the oxygen vacancy sites and $\mathrm{Li}^{+}$diffuses interstitially through the zirconium oxide shell. The carbonation reaction is limited by the solid state transport of $\mathrm{CO}_{2}, \mathrm{Li}^{+}$and $\mathrm{O}^{2-}$ in the lithium carbonate and zirconium oxide shells. Since the sizes of $\mathrm{Li}^{+}$and $\mathrm{O}^{2-}$ ions are much smaller than the molecule size of $\mathrm{CO}_{2}$, the diffusion of $\mathrm{CO}_{2}$ in the solid lithium carbonate layer is expected to be much slower than the diffusion of $\mathrm{Li}^{+}$and $\mathrm{O}^{2-}$ ions in the zirconium oxide shell. Therefore the former is more likely to be the rate-limiting step.

In the case of modified lithium zirconate (Fig.1 (c) to (d)), mixture of Li/K carbonates layer covering lithium zirconate will be melt and become a liquid layer (this is referred to as a molten carbonate) because of its lower melting point. After that, $\mathrm{CO}_{2}$ diffuses through the molten carbonate layer and reacts with lithium zirconate. In this case, lithium carbonate formed during the carbonation reaction is mixed with the molten carbonate to increase the volume of the molten carbonate layer. The diffusion of $\mathrm{CO}_{2}$ in the molten carbonate, with a diffusivity of about $10^{-5} \mathrm{~cm}^{2} / \mathrm{s} \mathrm{in}$ $500-600^{\circ} \mathrm{C}(3-6)$, is much faster than that in the solid carbonate. This can explain well the higher $\mathrm{CO}_{2}$ sorption rate in the case of modified lithium zirconate. This suggests that the doped lithium zirconate can be a good sorbent for high temperature carbon dioxide separation. However, the membrane made of either pure and doped lithium zirconate would not function properly. A fresh $\mathrm{Li}_{2} \mathrm{ZrO}_{3}$ membrane, once exposed to $\mathrm{CO}_{2}$ gradient, will convert to $\mathrm{ZrO}_{2}$ and lithium carbonate. This initial step during the use of the membrane is accompanied with phase change and structural rearrangement. The membrane can not maintain the mechanical integrity for continuous separation of carbon dioxide.

\section{CONCLUSION}

In this half year of Year II research, we focused on understanding the $\mathrm{CO}_{2}$ sorption/desorption mechanism on lithium zirconate. Considering the all obtaied data, we proposed a double layer model to describe the $\mathrm{CO}_{2}$ sorption/desorption behaviar of lithium zirconattte. In the model, final product after $\mathrm{CO}_{2}$ sorption is a particle which consist of $\mathrm{ZrO}_{2}$ core inside and $\mathrm{Li}_{2} \mathrm{CO}_{3}$ layer. In the pure $\mathrm{Li}_{2} \mathrm{ZrO}_{3}$, the formation of solid $\mathrm{Li}_{2} \mathrm{CO}_{3}$ shell inhibits transport of $\mathrm{CO}_{2}$, resulting in very slow carbonation rate. On the other hand, doping $\mathrm{K}_{2} \mathrm{CO}_{3} / \mathrm{Li}_{2} \mathrm{CO}_{3}$ in $\mathrm{Li}_{2} \mathrm{ZrO}_{3}$ helps trasforming the solid carbonate film to the liquid one during the carbonation reaction. $\mathrm{CO}_{2}$ diffusion in this liquid (molten) carbonate film is very fast, promoting $\mathrm{CO}_{2}$ sorption rate considerably.

These results show that $\mathrm{Li}_{2} \mathrm{ZrO}_{3}$ is potentially an excellent sorbent for separation of $\mathrm{CO}_{2}$ at high temperature. However, pure $\mathrm{Li}_{2} \mathrm{ZrO}_{3}$ is not a good material for the $\mathrm{CO}_{2}$ semi-permeable membrane proposed originally. Nevertheless, the $\mathrm{CO}_{2}$ sorption and microstructure results of the $\mathrm{K}_{2} \mathrm{CO}_{3} / \mathrm{Li}_{2} \mathrm{CO}_{3}$ doped $\mathrm{Li}_{2} \mathrm{ZrO}_{3}$ show that molten carbonate is highly $\mathrm{CO}_{2}$ semi-permeable. The 
molten carbonate, if imbedded in a metal mesh, will give a $\mathrm{CO}_{2}$ permeability larger than 0.5-2 $\mathrm{x} 10^{-11} \mathrm{~mol} / \mathrm{m} . \mathrm{s} . P a$ at $600{ }^{\circ} \mathrm{C}$. With these results, we have decided to pursue the direction of preparing high temperature $\mathrm{CO}_{2}$ perm-selective membrane using the molten carbonate material instead of lithium zirconate. Based on the understanding of $\mathrm{CO}_{2}$ sorption mechanism for lithium zirconate conducted in Year I of phase I project, we proposed to develop a new $\mathrm{CO}_{2}$ permselective dense dual-phase inorganic membrane for separation of $\mathrm{CO}_{2}$ from the flue gas in the temperature range of $350-550^{\circ} \mathrm{C}$.

\section{LITERATURE CITED}

(1) R. Stevens, Zirconia and Zirconia Ceramics, Magnesium Elektron Ltd., Twickenham, UK (1986)

(2) Y.S. Lin, K.J. de Vries, H.W. Brinkman and A.J. Burggraaf, J. Membrane Sci., 66, 211226(1992)

(3) P. Claes, B. Thirion and J. Glibert, Solubility of $\mathrm{CO}_{2}$ in the Molten $\mathrm{NaCO}_{3}-\mathrm{K}_{2} \mathrm{CO}_{3}$ (42mol\%) Eutectic Mixture at $800{ }^{\circ} \mathrm{C}$, Electrochimica Acta, 41 (1996) 141-146.

(4) P.L. Spedding and R. Millis, J. Electrochem. Soc., 113, 559 (1965).

(5) P.L. Spedding and R. Millis, J. Electrochem. Soc., 113, 594 (1965).

(6) P.L. Spedding, J. Electrochem. Soc., 117, 177 (1970). 


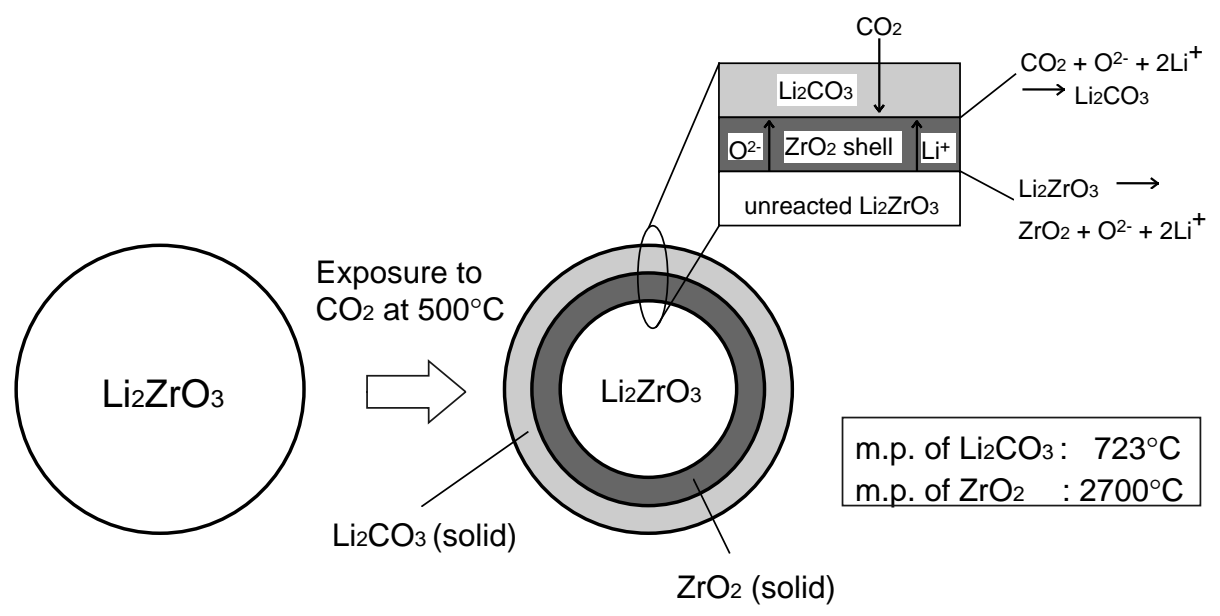

(a)

(b)

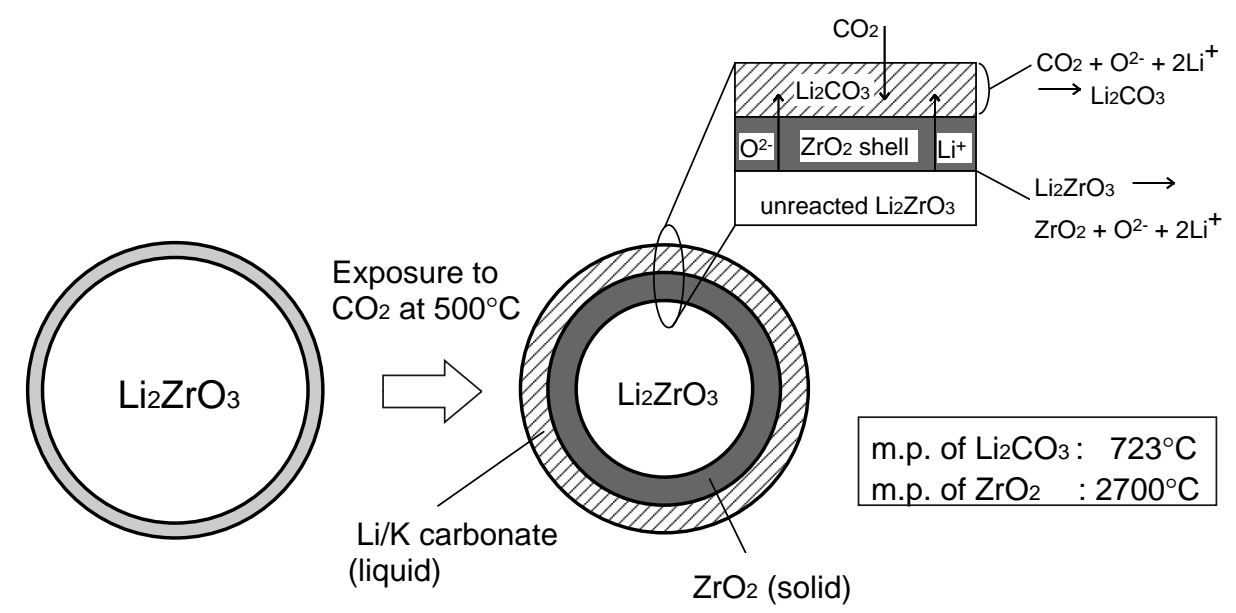

(c)

(d)

Fig.1 Schematic illustration of carbonation mechanism on pure and modified $\mathrm{Li}_{2} \mathrm{ZrO}_{3}$ 